\title{
DIAGNOSIS OF SPERMATIC GRANULOMA BY FINE NEEDLE ASPIRATION
}

\author{
Dr. Shashidhar H B, Dr. Vani. D, Dr. Sushma S, Dr. Bharathi M
}

1. Assistant Professor, Department of Pathology, Mysore Medical College and Research Institute, Mysore

2. Assistant Professor, Department of Pathology, Mysore Medical College and Research Institute, Mysore

3. Post Graduate Student, Department of Pathology, Mysore Medical College and Research Institute, Mysore

4. Professor, Department of Pathology, Mysore Medical College and Research Institute, Mysore

\section{CORRESPONDING AUTHOR-}

Dr. Shashidhar H B

Assistant Professor of Pathology,

No 9, Doctors quarters, JLB Cross Road, Devaraj Mohalla,

Mysore, Karnataka.

Ph: 9448048774,

E-mail ID: shbmysore@gmail.com

\begin{abstract}
:
Spermatic granuloma is an uncommon non-neoplastic granulomatous lesion. There are only a few documented cases of cytologically diagnosed spermatic granuloma in literature. Fine needle aspiration cytology (FNAC) reveals mixed inflammatory cell infiltrate with many spermatozoa and sperm-heads present within macrophages and outside. FNAC provides a rapid and specific diagnosis and it can rule out neoplastic and other benign inflammatory conditions, thereby preventing unnecessary surgical intervention.
\end{abstract}

KEY WORDS: Spermatic Granuloma, Epitheloid cells, Testis

\section{INTRODUCTION:}

Spermatic granuloma is a granulomatous lesion caused due to extravasation of spermatozoa into the stroma of epididymis.

It presents as a painless nodule mimicking a testicular tumour.1Cytological features of spermatic granuloma are specific. Fine Needle Aspiration (FNA) has an important role in that, it can rule out malignancy and other benign conditions. 2

\section{CASE REPORT:}

Two cases of spermatic granuloma were reported on FNAC in the department of pathology, Mysore Medical College and Research Institute, Mysore over a period of 3 years. The patients were aged about 28 years and 34 years and both presented with a painless paratesticular nodule.

There was no history of trauma or surgery in either case. Clinically, one of the cases was diagnosed as spermatocele and the other as epididymal nodule.

FNA of the nodule was done using 23 gauge needle under local anesthesia and absolute aseptic precautions. The smears were stained with Haematoxylin and Eosin, Ziehl - Neelsen and Leishmann stains.

Journal of Evolution of Medical and Dental Sciences/Volume 1/Issue 2/April-June 2012 
The smears in both the cases were highly cellular. Microscopy revealed mixed inflammatory cell infiltrate rich in macrophages and histiocytes with polymorphs and scattered epithelioid cells in the background (fig1). Many spermatozoa and sperm-heads were present both within macrophages and outside. However, multinucleated giant cells were not seen in both the cases (fig2).

Histopathological confirmation was available in both the cases. Culture and ziehl -neelsen stain for the demonstration of acid fast bacilli were negative in both the cases.

\section{DISCUSSION:}

Spermatic granuloma is a non-tuberculous granulomatous lesion. The granulomatous reaction may be chemical in nature since the spermatozoa contain an acid fast lipid mycolic acid similar to the lipid that is found in tubercle bacilli.3

The important differential diagnoses under non-neoplastic lesions include tuberculous epididymo-orchitis and malakoplakia. These conditions were ruled out based on clinical findings, microscopic features and special stains like ziehl -neelsen stain for AFB, Perl's stain for MichaelisGuttman bodies and Von-Kossa stain for calcium.

The important differential diagnoses considered and ruled out under neoplastic conditions include adenomatoid tumor and seminoma. In adenomatoid tumor, the cells are arranged in dyscohesive sheets with eccentrically pushed nuclei and small central nucleoli. In seminoma, the tumor cells are admixed with abundant lymphocytes and may thus mimic inflammatory lesions.

In conclusion, FNAC can provide rapid and specific diagnosis besides ruling out malignancy and other benign conditions, thereby relieving the patient's anxiety and avoiding unnecessary surgical intervention as the patient can be alternatively managed by conservative therapeutic approach.

However, adequate samples with abundant cellularity and key diagnostic features are imperative for a definitive diagnosis of spermatic granuloma on FNAC.

\section{REFERENCES:}

1)Glassy FJ, Mastofi FK. Spermatic Granuloma of the Epididymus. Am J Clinical Pathol 1956; 26:1303-13.

2)Rajwanshi A, Gupta RK. Cytological findings in Spermatic Granuloma. Acta Cytol 1990; 347:63-4. 3)Berg JW. An Acid -Fast lipid from spermatozoa. Arch Pathol.1954; 57:115-20.

4)Pareze-Guillermo PM, Thor A, Loehagen T. Spermatic granuloma diagnosis by Fine needle aspiration

cytology. Acta Cytol 1989; 33: 1-5.

\section{ACKNOWLEDGEMENT:}

We express our sincere thanks to Dr. Avadhani Geetha K., Dean \& Director, Mysore Medical College $\&$ Research Institute, Mysore for the kind permission to publish this case report.

Journal of Evolution of Medical and Dental Sciences/Volume 1/Issue 2/April-June 2012 


\section{CASE REPORT}

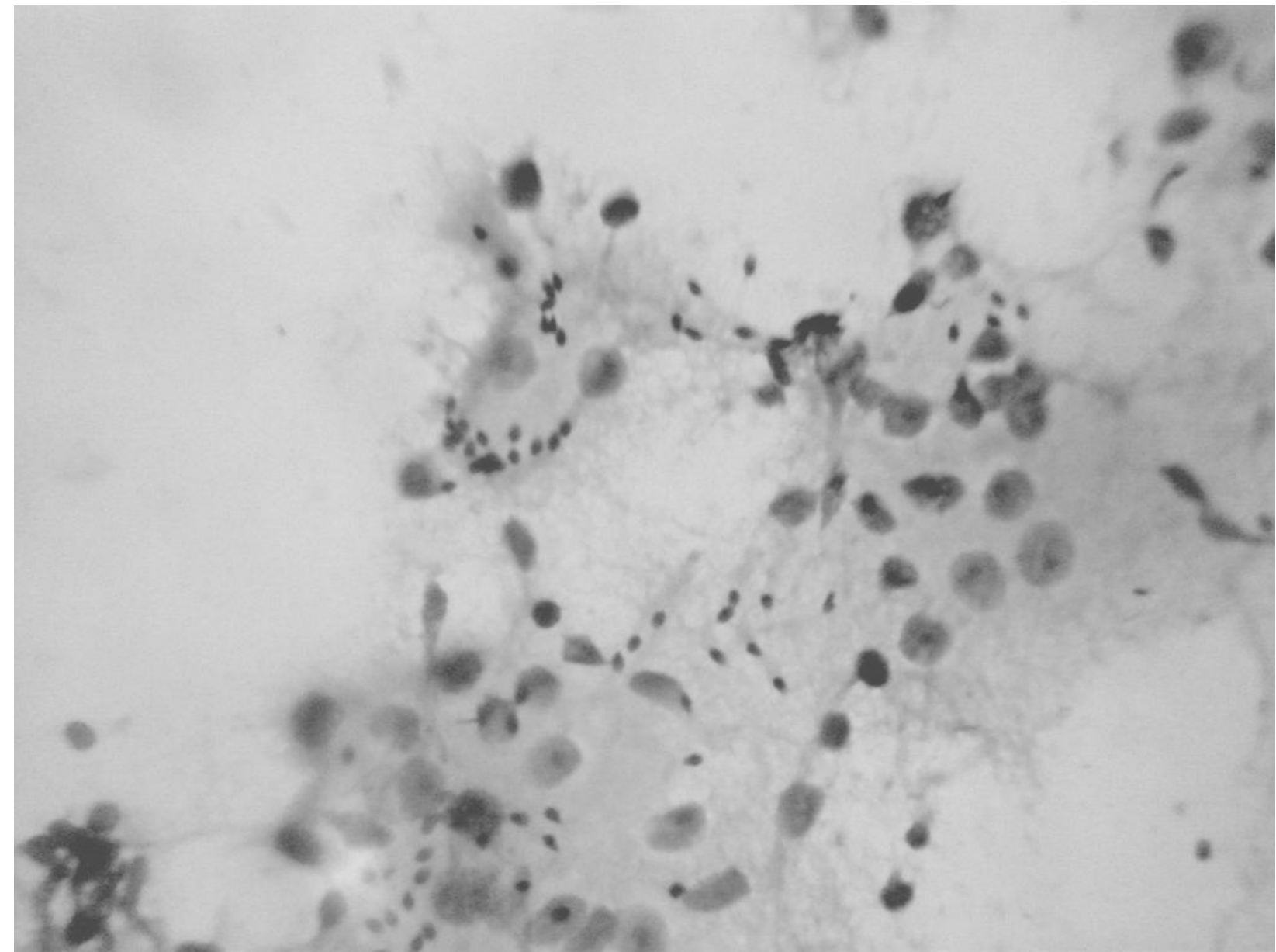

FIG 1: FNA Smear: microscopy

Inflammatory cell infiltrate rich in macrophages and histiocytes with polymorphs and scattered epithelioid cells in the background. 


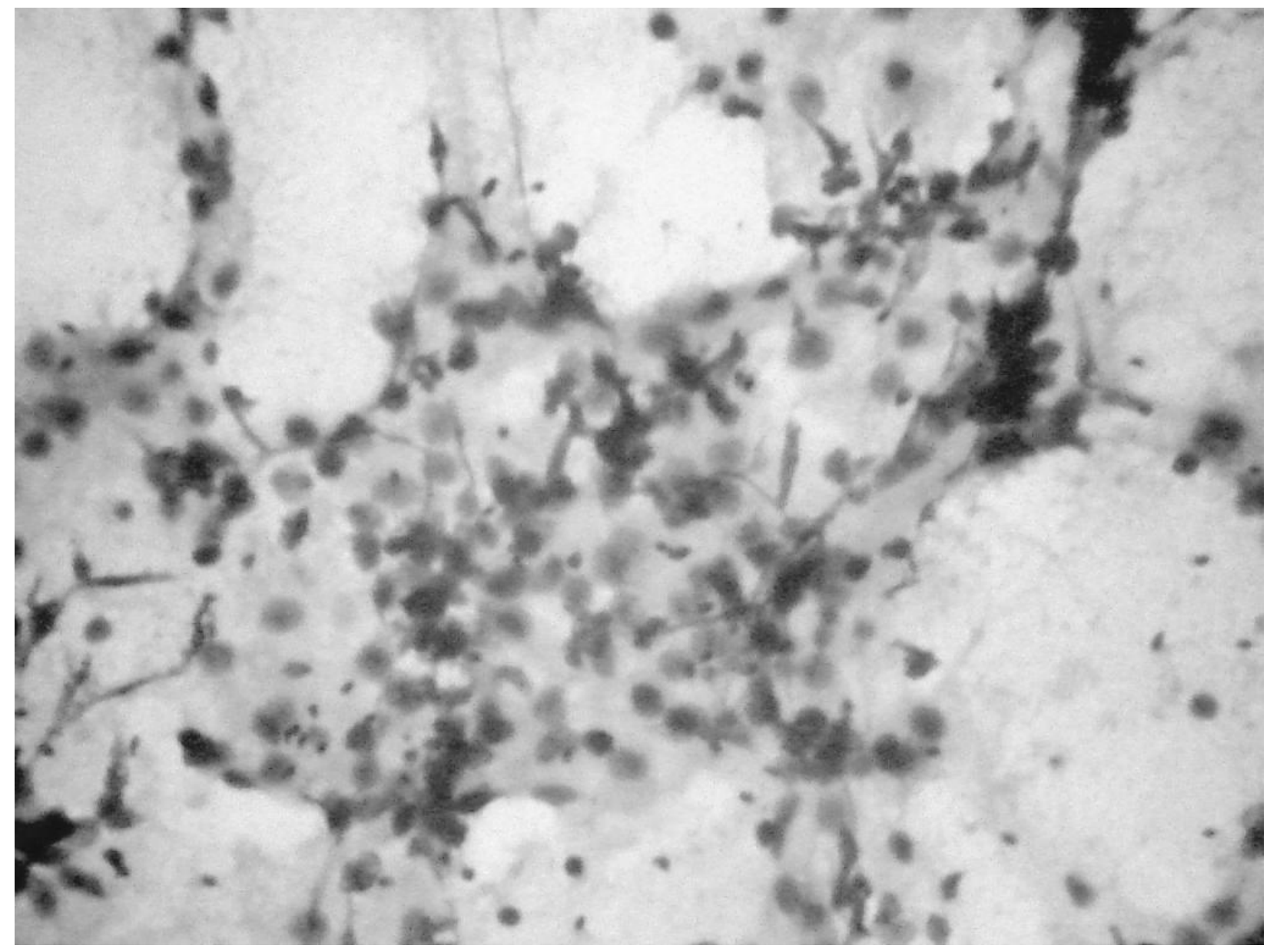

FIG 2: FNA Smear: microscopy

Many spermatozoa and sperm heads were present both within macrophages and outside. 